\title{
Quantification of Fibronectin Adsorption to Silicone-Rubber Cell Culture Substrates
}

BioTechniques 32:876-887 (April 2002)

\author{
James J. Cunningham, Janeta \\ Nikolovski, Jennifer J. Lin- \\ derman, and David J. Mooney \\ The University of Michigan, \\ Ann Arbor, MI, USA
}

\begin{abstract}
As the role of mechanical force in cellular signaling gained recognition, investigators designed a number of devices to deliver controlled regimens of mechanical force to cultured cells. One type of device uses thin silicone-rubber membranes to support monolayer cell adhesion and to transmit mechanical force in the form of biaxial strain. We have observed that cell attachment and spreading are impaired on these membranes compared to polystyrene, even when both are passively coated with identical amounts of extracellular matrix. The purpose of these studies was to quantify the efficiency and stability of passive matrix adsorption onto commercially available elastic culture substrates. A theoretically saturating density $\left(1 \mu \mathrm{g} / \mathrm{cm}^{2}\right)$ of fibronectin was added to each well, and the initial efficiency of adsorption to the walls and elastic membranes was found to be $31 \pm 2 \%$ of the protein added. Strikingly, when the protein adsorbed specifically to the membranes was quantified after seven days, only 10-26 $\mathrm{ng} / \mathrm{cm}^{2}$ fibronectin were present, revealing that most of the adsorption is to the sides of the wells. These results indicate that the adsorption of matrix proteins to silicone-rubber substrates is relatively inefficient and that investigators who use these systems must be aware of this fact and design their experiments accordingly.
\end{abstract}

\section{INTRODUCTION}

Mechanical forces are increasingly recognized as important regulators of cell growth and function, and recent studies have begun to unravel the role of mechanical force in cellular signaling $(3,11,20)$. Many different types of devices have been used to apply mechanical force to cells cultured in both 2-D and 3-D systems $(9,13,26,29)$. A popular type of device to stretch cells grown in 2-D monolayer culture uses thin silicone-rubber substrates to support cell adhesion and transmit strain. Several variations on this theme have been designed by a number of research groups $(1,9,14,20,22,25)$, and this type of device has been automated and made commercially available in the form of the Flexercell ${ }^{\circledR}$ System (Flexcell International, McKeesport, PA, USA) $(5,26)$. In many of these devices, the membranes are deformed by stretching over a stationary loading post positioned at the center of each well, either by applying a vacuum pressure to the underside of the silicone membranes (Flexercell System) or by simply moving the wells and loading posts relative to each other. Strain applied to the silicone culture membranes of these devices is transmitted to adherent cells via extracellular matrix (ECM) proteins that interact both with the culture surface and with transmembrane integrin receptors on the cell (30).

Therefore, a crucial variable in these systems is the method by which ECM proteins are deposited on the surface of the material to support cell adhesion. It is likely that different surface-protein interactions and different densities of cell adhesion ligands might support different levels of force transfer. The BioFlex ${ }^{\circledR}$ plates used with the Flexercell system are available from the manufacturer precoated with various ECM proteins, or the plates can be coated in the laboratory before performing the experiments. Because there is no information available from the manufacturer concerning the surface concentration of ECM on the precoated plates, we have chosen to coat them ourselves. An established method of coating ECM molecules onto cell culture surfaces is the passive adsorption of the protein from a basic bicarbonate buffer (10).

Although the interaction of cells with a biomaterial is governed initially by ECM proteins that have been purposefully immobilized on the surface, other proteins will adsorb from solution over time (6). In situations where serum is present, fibronectin and vitronectin are the two primary adhesion proteins found to adsorb to biomaterials $(19,27)$. Indeed, vitronectin may be the most important mediator of cell adhesion under certain conditions because cells have been observed to clear fibronectin, but not vitronectin, from their focal adhesions when cultured on glass in the presence of serum (18). To maintain more control over cell-material interactions, researchers often culture in defined, serum-free media or use materials that are incapable of supporting protein adsorption, such as alginate hydrogels (23). Over time, cells will remodel their environment by secreting ECM proteins and organizing them into a new ECM.

The purpose of this study is to char- 
acterize the efficiency of the passive adsorption of matrix proteins to siliconerubber substrates and the stability of the coated protein over time. Fibronectin was used as a model adhesion protein because it has been well characterized and is a physiologically important mediator of cell adhesion. Human plasma fibronectin with trace amounts of $125 \mathrm{I}$ labeled fibronectin (ICN, Irvine, CA, USA) was used to determine the amount of protein that adsorbed initially and the amount that dissociated from the surface over a period of one week. The studies were performed in defined, serum-free culture medium to limit the uncontrolled adsorption of other adhesion proteins onto the culture surface. Clearly, under less stringent conditions, other adhesion proteins such as vitronectin may also mediate cell adhesion and exhibit very different adsorption characteristics compared to fibronectin. The roles of cells and strain in altering the stability of the protein coating were investigated in these studies. The pretreatment of the culture surface with UV radiation from a UV sterilization bulb was also tested as a means of activating the surface in a manner analogous to the gas-plasma treatment of tissue culture polystyrene (6).

Knowledge of the density of ECM molecules on the culture surface is critical in interpreting strain experiments because strain transmission from the membrane to the cells depends in part on the number and type of bonds that form between the two. Above a certain ECM density, the spacing between adjacent ECM molecules is sufficiently small to allow the clustering of integrin receptors and the formation of focal adhesions that may be necessary for the efficient transfer of mechanical force between the substrate and the cell (2). The minimum necessary spacing of covalently immobilized Arg-Gly-Asp (RGD) peptides, the primary adhesion ligand found in many ECM molecules, has previously been verified to be 140 $\mathrm{nm}$ for human foreskin fibroblasts, corresponding to a surface concentration of $10 \mathrm{fmol} / \mathrm{cm}^{2}$ (16). Below this concentration, cell adhesion ligands are too widely spaced to allow focal adhesion formation. The threshold surface density needed for focal adhesion formation with passively adsorbed ECM proteins is likely to be much higher because much of the adsorbed protein will be in the incorrect orientation or conformation to promote adhesion effectively. Controlling the specific density of ECM molecules present on a culture surface is likely to be critical in determining the response of cells to the mechanical signals provided via the surface.

\section{MATERIALS AND METHODS}

In these studies, the adsorption of adhesion proteins to BioFlex six-well culture dishes with deformable elasticbottom surfaces (Flexcell International) was investigated. The plates were passively coated with ECM at a theoretically saturating density of $1 \mu \mathrm{g} / \mathrm{cm}^{2}$ using the carbonate buffer method (10). Briefly, type I collagen (Vitrogen ${ }^{\circledR} 100$, $3 \mathrm{mg} / \mathrm{mL}$; Cohesion, Palo Alto, CA, USA) or human plasma fibronectin (1 $\mathrm{mg} / \mathrm{mL}$; Invitrogen, Carlsbad, CA, USA) was solubilized in carbonate buffer $\left(15 \mathrm{mM} \mathrm{Na}_{2} \mathrm{CO}_{3}, 35 \mathrm{mM} \mathrm{NaH}\right.$ $\mathrm{CO}_{3}$, pH 9.4, with glacial acetic acid; reagents from Sigma, St. Louis, MO, USA) and incubated overnight on the surface to be coated. The plates were then rinsed twice with cold PBS before seeding them with cells. Smooth muscle cells (SMCs) were isolated from the excised aortas of young male Lewis rats by enzymatic digestion (21). For a qualitative determination of the extent of cell spreading, cells were seeded onto ECM-coated bacteriologic sixwell plates and BioFlex dishes at a density of 100000 cells/well in defined, serum-free media [CSC SF Media Kit supplemented with RocketFuel additive (1:50); Cell Systems, Kirkland, WA, USA]. After two days, the extent of cell spreading was determined by phase contrast microscopy.

The efficiency and stability of ECM adsorption to the BioFlex cell culture plates were determined by including trace amounts of 125I-labeled fibronectin $(1 \mu \mathrm{Ci} / \mu \mathrm{g})$ in the coating mixture. The concentration of fibronectin in the coating mixture was $4.34 \mu \mathrm{g} / \mathrm{mL}$. Fibronectin was labeled by the chloramine $\mathrm{T}$ method and purified by size-exclusion HPLC. Free iodide was determined by trichloracetic acid precipitation to be less than $5 \%$.
Radiolabeled fibronectin was used at a ratio of 1:375 (by weight) with unlabeled fibronectin. After an overnight incubation at $4^{\circ} \mathrm{C}$, the coating solution was removed and the plates were rinsed twice with PBS. Culture medium or medium plus SMC (100 000 cells/well) was then added to the dishes that were placed in a $37^{\circ} \mathrm{C}$ incubator and either exposed to cyclic strain $(0.25 \mathrm{~Hz}, 7 \%)$ using the Flexercell strain unit or left unstrained. At 48-h intervals up to seven days after the coating, the samples of culture media were removed. The PBS washes and media samples were counted on a $\gamma$ counter to determine the radioactive fibronectin content. Tissue culture-treated and bacteriologic polystyrene six-well dishes were used as controls, as was adsorption from plain PBS. The effect of activating the silicone-rubber surface via UV irradiation before coating with fibronectin was also investigated. Plates were exposed overnight to UV radiation from the sterilization bulb in a standard cell culture hood. At the end of the seven-day timecourse, the membranes were cut out with a scalpel and counted on a $\gamma$ counter to quantify the fibronectin adsorbed specifically to the membranes.

\section{RESULTS}

These studies were motivated by the initial observation that the extent of cell attachment and spreading on siliconerubber surfaces is typically much less than on polystyrene. In the first experiment, SMCs were seeded onto identically coated BioFlex and bacteriologic polystyrene plates, and the extent of spreading on each was determined. The experiments were performed with plates coated with both collagen and fibronectin. After two days in culture, nearly all cells that had been seeded onto polystyrene were adherent and well spread, while those seeded on BioFlex dishes were poorly spread and many were not attached at all (Figure 1, A and B). Similar results were obtained with cells on both types of purified matrix molecule.

To investigate whether this lack of adhesion and spreading is due to differences in the amount or stability of the ECM adsorbed to each type of plate, 


\section{Research Report}

the fibronectin adsorption was quantified using radiolabeled protein. The initial efficiency of adsorption and the stability of the coating under cell culture conditions for seven days were determined. Cells were included in some of the wells to determine if they enhanced the dissociation of matrix from the BioFlex membranes, and the effect of cyclic strain was also investigated. The initial efficiency of adsorption of fibronectin to BioFlex wells (including the membranes and walls of the wells) was $31 \pm 2 \%$ of the protein added or $310 \pm 20 \mathrm{ng} / \mathrm{cm}^{2}$ (Figure 2). An overnight exposure to UV radiation under a cell culture hood had no statistically significant effect on this result. For comparison, the initial adsorption to tissue culture-treated and bacteriologic polystyrene plates was $25 \pm 1 \%$ and $27 \pm 1 \%$, respectively. When PBS was used as the adsorption buffer, similar results were obtained on both bacteriologic and tissue culture-treated dishes, with $32 \pm 2 \%$ and $23 \pm 1 \%$ adsorbing, respectively. These values are roughly comparable to those reported previously in the literature $(7,17,28)$. Doubling the concentration of the fibronectin added to the wells increased the absolute amount of the fibronectin coated but decreased the overall efficiency to $25 \pm 2 \%$ (data not shown).

The adsorbed fibronectin was found to be relatively stable, with the most dissociation occurring in the first $24 \mathrm{~h}$, leaving $82 \%-94 \%$ of the initially bound fibronectin in the wells after this time in all conditions (Figure 3). UV pretreatment did enhance the stability of the adsorbed fibronectin by an average of $6 \%$. Furthermore, the presence of both cells and strain had reproducible effects on fibronectin stability. Cells enhanced the dissociation of fibronectin from the wells by an average of $1 \%$ after seven days in the culture (data not shown). Strain stabilized the adsorbed fibronectin, reducing the dissociated protein by an average of $4 \%$ after seven days in the culture.

The studies were designed to measure the amount of fibronectin dissociating from the wells, giving an indirect measure of fibronectin on the surface. To measure the protein specifically adsorbed to the culture membrane (as opposed to the sides of the wells), the sili- cone membranes were cut out of the wells on the seventh day and assayed for fibronectin. The most striking finding was that nearly all of the adherent fibronectin was actually on the walls of the dishes and not on the silicone membrane to which the cells attach. On average, only $2 \%$ of the fibronectin originally added (or about $20 \mathrm{ng} / \mathrm{cm}^{2}$ ) was present on the membrane itself after seven days. The effect of the cells and strain on the stability of this fibronectin was much more pronounced, with both cells and strain significantly decreasing the amount of fibronectin left on the membranes after seven days (Figure 4). On the other hand, UV pretreatment significantly increased the amount of protein on the membrane, as expected.

\section{DISCUSSION}

In these studies we have performed a characterization of ECM adsorption to flexible silicone-rubber cell culture membranes. These membranes, in the form of BioFlex cell culture plates and

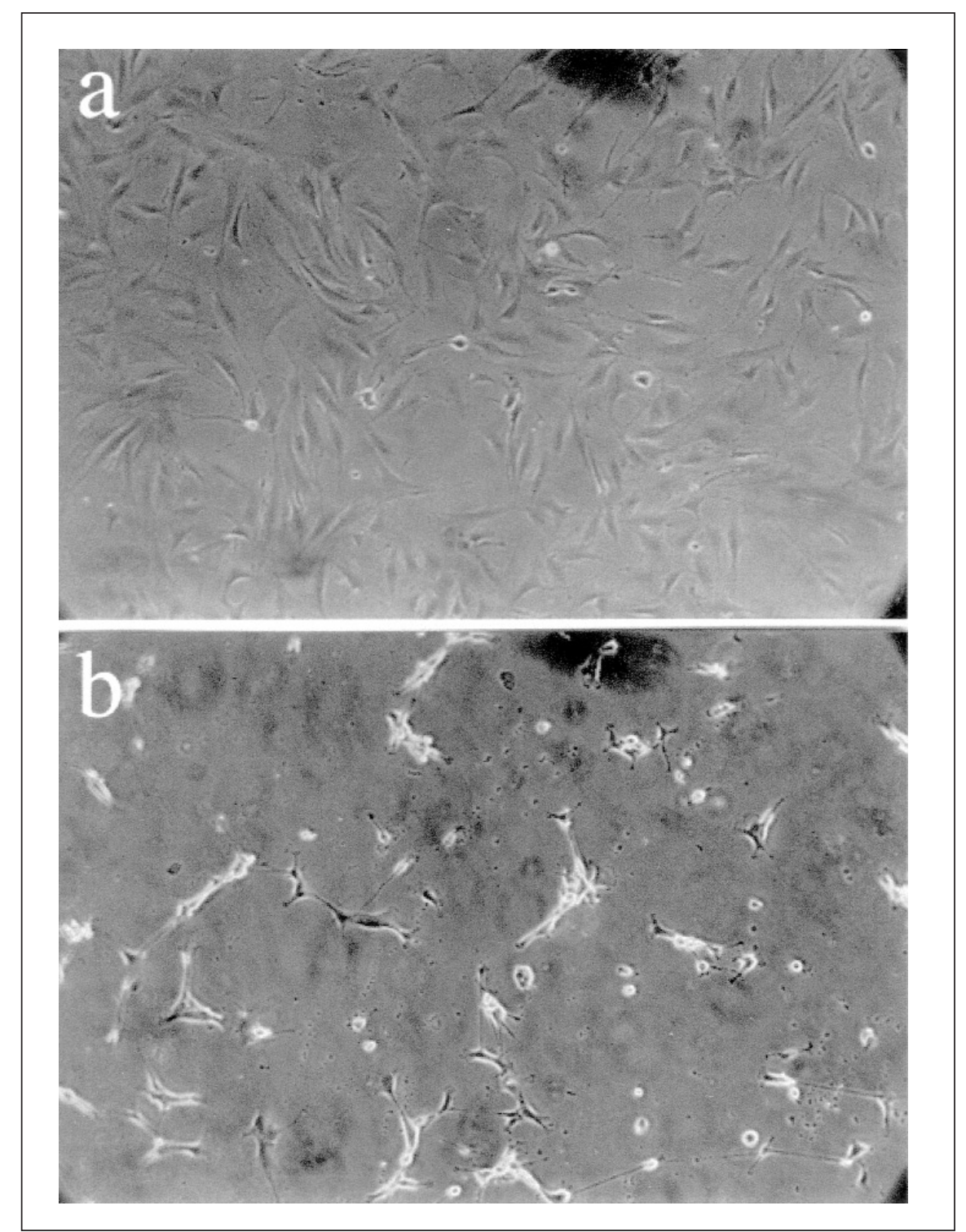

Figure 1. The extent of cell spreading on silicone-rubber membranes compared to polystyrene. Representative phase contrast micrographs of rat aortic SMCs two days after seeding onto (A) bacteriologic polystyrene six-well dishes and (B) silicone-rubber culture dishes. Both surfaces were coated with collagen at a theoretical density of $1 \mu \mathrm{g} / \mathrm{cm}^{2}$ before cell seeding. Results on fibronectin-coated surfaces were similar. 
others, have been used in a number of recent studies testing the effect of strain on cells $(12,15,20,24)$. To our knowledge, no previous characterization of passive ECM adsorption to BioFlex membranes has been carried out, and we believe these findings provide important information that is crucial to interpreting past results and designing future experiments. Our own previous work with these membranes has indicated that cell adhesion and spreading are significantly different on these materials compared to polystyrene, even when both surfaces are passively coated with a theoretically saturating density of ECM. This finding is not particularly surprising, but it suggests that matrix adsorption to the two surfaces may be radically different and that one cannot simply assume that the ECM added to these membranes actually adsorbs in a useful fashion. Two main factors that affect cell adhesion to adsorbed matrix molecules are the number or concentration of those molecules and the conformation or orientation of those molecules on the surface. These studies were designed to specifically measure only the amount of matrix on the surface.

Our findings revealed that approximately $32 \%$ of the added protein initially adsorbed to the BioFlex wells. This was comparable to adsorption levels on polystyrene control plates. More fibronectin bound to bacteriologic plates than cell culture-treated plates, suggesting that hydrophobic surfaces actually have a higher binding capacity for fibronectin than hydrophilic ones, which is in agreement with previous findings (7). A variable that is likely to be very different on bacteriologic plates and tissue culture plastic is the biological activity of the adsorbed protein, which depends on the maintenance of a native conformation. Hydrophilic surfaces tend to preserve protein activity better than hydrophobic ones because protein denaturation is promoted by the strong, irreversible binding that occurs on hydrophobic surfaces $(8,28)$. Although untreated BioFlex membranes appear to be highly hydrophobic, we speculate that UV irradiation decreases the surface hydrophobicity.

Our results indicated that fibronectin was removed from the wells over time, with as much as $25 \%$ of the protein having desorbed by the seventh day. Although the presence of both cells and strain altered the stability of the adsorbed protein in a small but consistent manner, the overall effect was less than a few percent of the adsorbed fibronectin. The most dramatic effect on the amount of adsorbed protein was that of the pretreatment with UV radiation. Activating the surface in this manner before the addition of the fibronectin significantly increased the amount of adsorbed protein over time. This study suggests that the 
stability of the protein adsorbed to the wells, rather than the initial efficiency of adsorption, was enhanced by UV pretreatment. In a manner analogous to the gas plasma treatment of tissue culture polystyrene, the exposure to UV light may create charged chemical moieties on the surface of the material that are likely to enhance protein interactions with the surface and possibly better preserve the biological activity of the adsorbed protein, although this was not tested in these studies.

The amount of ECM protein that adsorbed specifically to the culture surface, as opposed to the walls of the wells, is clearly the important factor in the transmission of forces between the silicone membrane and the cells. For this reason, the membranes were cut out of the wells at the end of the experiment, and the protein specifically adsorbed to them was quantified. Strikingly, only a small fraction of the adsorbed protein was present on the silicone membranes after seven days, compared to the sides of the dishes. Not surprisingly, the effects of cells and strain were much more pronounced when examining the isolated membranes, increasing the dissociation of protein by as much as 2 -fold. This results in a relatively low protein coating $\left(10-20 \mathrm{ng} / \mathrm{cm}^{2}\right)$ on the cell culture surface. Similar adsorption studies performed on another type of flexible silicone substrate (Flex I ${ }^{\circledR}$ plates; Flexcell International) have revealed that several times more fibronectin can adsorb to those membranes (30). However, taken in the context of the minimum RGD surface concentration of $10 \mathrm{fmol} / \mathrm{cm}^{2}$ (approximately $2.2 \mathrm{ng}$ fibronectin $/ \mathrm{cm}^{2}$ ) needed to promote focal adhesion formation, the amounts of surface-adsorbed fibronectin we have measured should certainly be sufficient to support strong cell attachment. We speculate that, because of the hydophobicity of the surface, the majority of this protein is adsorbed so that the adhesion sites are unavailable to the cells. The number of protein molecules adsorbed in an orientation that is useful to the cells may well be less than $10 \mathrm{fmol} / \mathrm{cm}^{2}$.

The results of these studies demonstrate that the silicone-rubber membranes of the BioFlex plates do not provide a favorable surface for fibronectin adsorption, at least under the conditions tested. The culture surfaces were coated with a fibronectin solution that corresponded to a surface density of 1 $\mu \mathrm{g} / \mathrm{cm}^{2}$, taking into account both the walls of the wells and the culture surface and assuming that all of the fibronectin in the solution adsorbed to

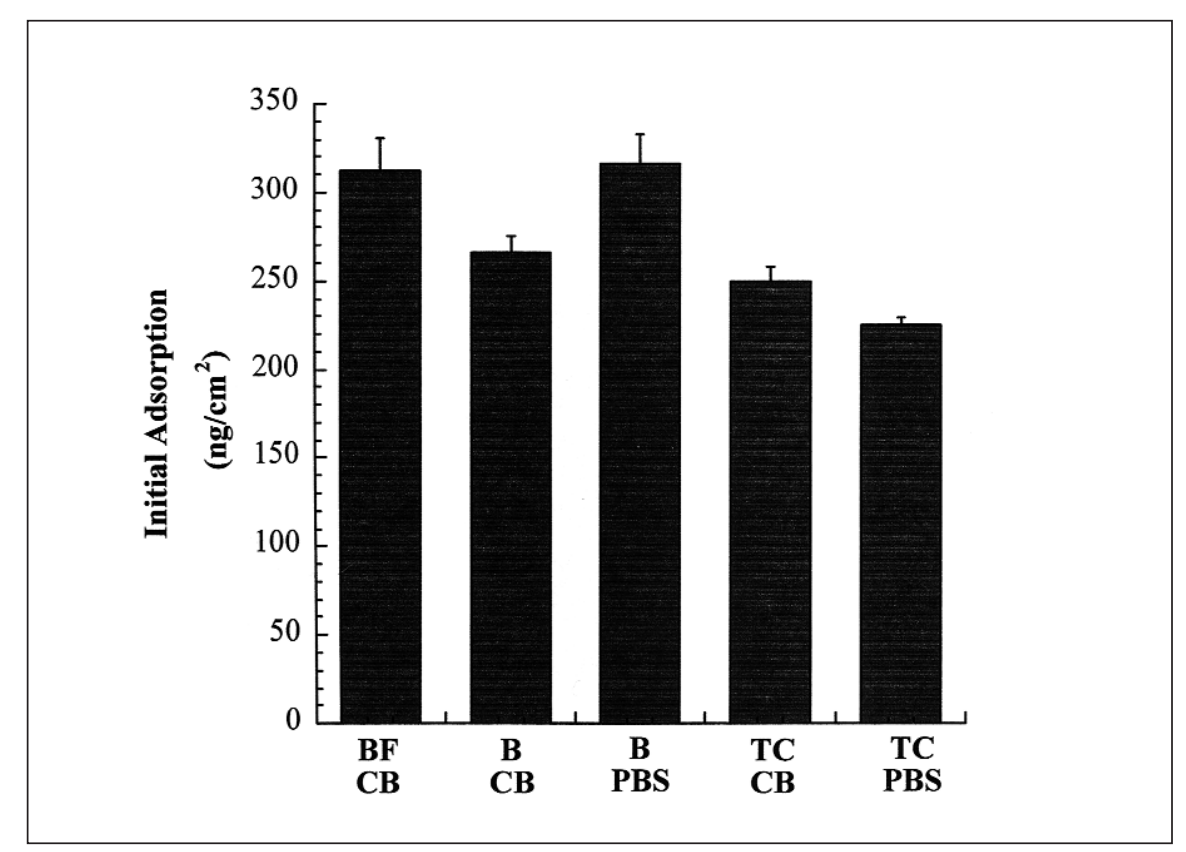

Figure 2. Initial adsorption of fibronectin to culture surfaces. Culture surfaces (BF, BioFlex plates; B, bacteriologic polystyrene; and TC, tissue culture polystyrene) were incubated with fibronectin at a concentration of $1 \mu \mathrm{g} / \mathrm{cm}^{2}$ in buffer (CB, carbonate buffer, $\mathrm{pH} 9.4$; PBS, $\mathrm{pH} 7.4$ ) overnight at $4^{\circ} \mathrm{C}$. The fibronectin that remained on the surface (mean \pm SD) after two washes in PBS is depicted for each condition. All differences are statistically significant $(P<0.05)$ from each other, except for $\mathrm{BF} / \mathrm{CB}$ compared to $\mathrm{B} / \mathrm{PBS}$ and $\mathrm{B} / \mathrm{CB}$ compared to TC/CB, as determined using the Student's $t$ test $(n=3)$.

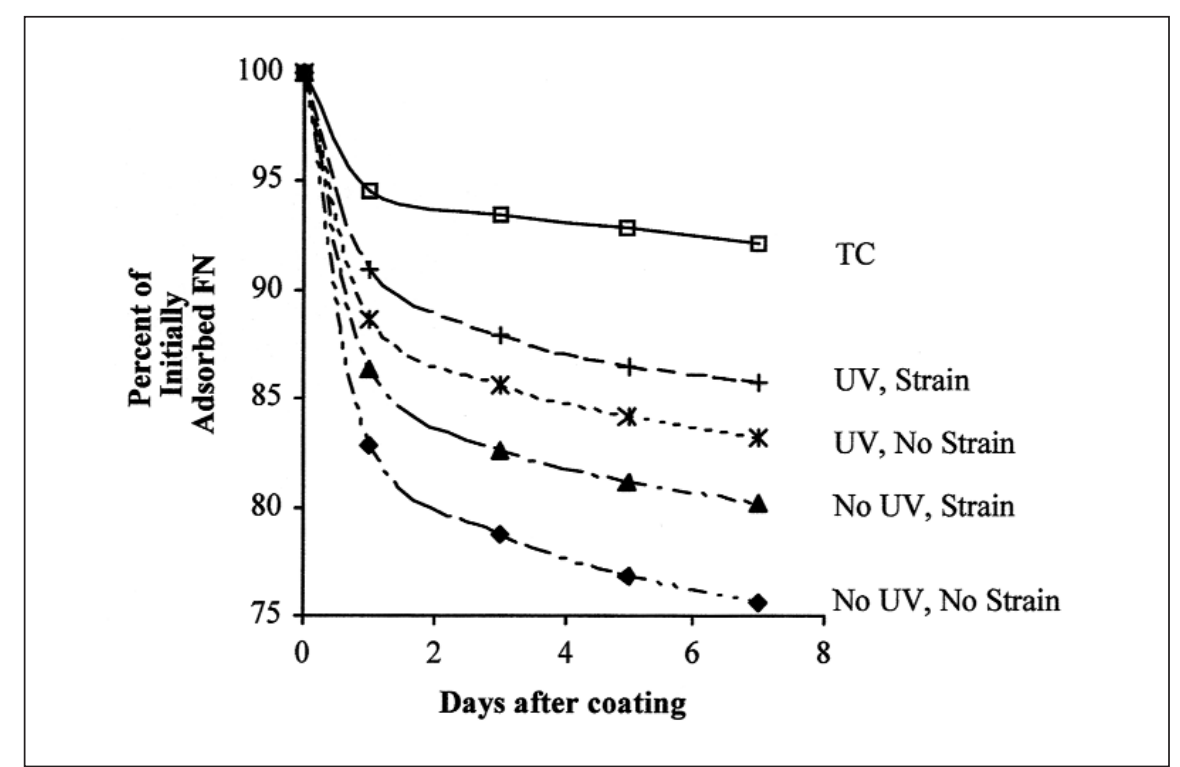

Figure 3. Stability of fibronectin coated on elastic membranes or tissue culture polystyrene over time as a percentage of the initial fibronectin adsorbed. The fibronectin released into the culture medium was monitored by measuring the soluble ${ }^{125} \mathrm{I}$ levels. Cells were present in all conditions at a seeding density of 100000 cells/well. Labels on the trendlines refer to the surface pretreatment and presence or absence of strain in each condition. TC, tissue culture polystyrene control $(n=3)$. Error bars have been omitted for clarity. 


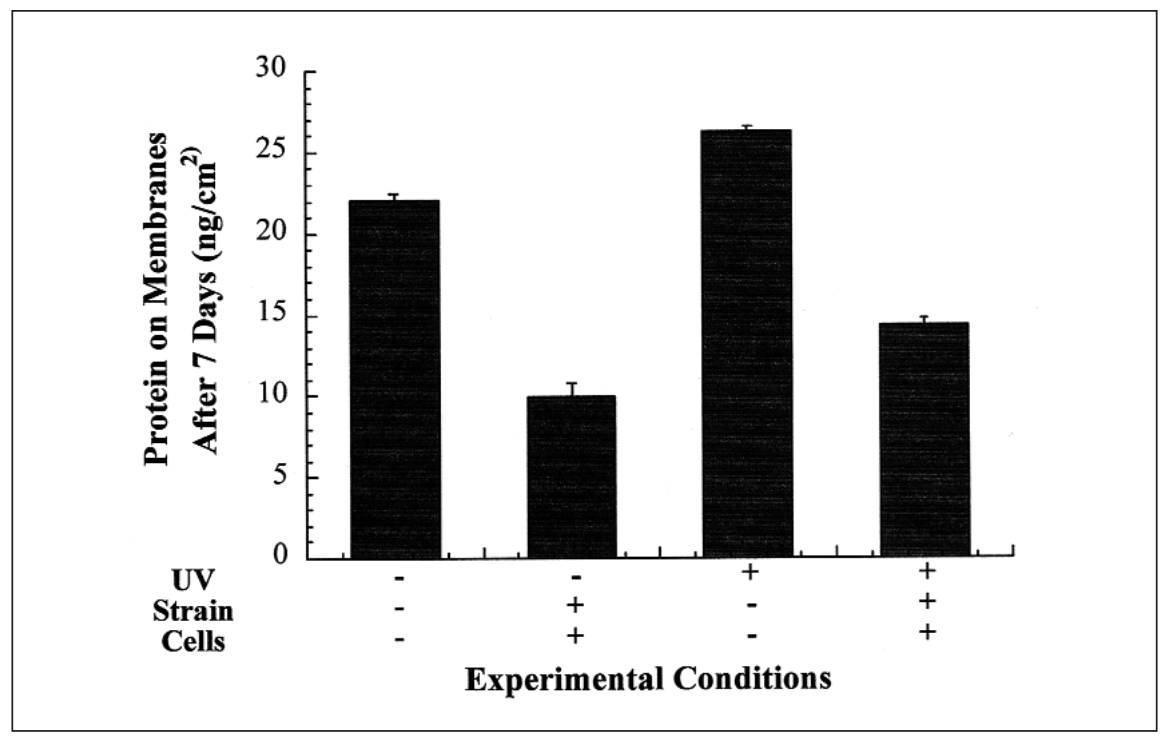

Figure 4. Fibronectin adsorbed to silicone membranes after seven days. Silicone-rubber membranes were cut out of the BioFlex plates after seven days, and the fibronectin adsorbed specifically to the membranes was quantified. The effects of the UV pretreatment of the membrane before coating, cyclic strain, and cells (100000/well initial seeding) were all investigated. UV pretreatment significantly increased the amount of protein, while cells and strain destabilized the adsorbed protein. Values represent the mean $(n=$ $3) \pm S D$, and all values are statistically different from each another, as determined using the Student's $t$ test. those two surfaces. Theoretical calculations based on the closest packing of fibronectin molecules in a monolayer suggest that the saturation of binding should be reached between 0.2 and 5 $\mu \mathrm{g} / \mathrm{cm}^{2}(4,7)$. The wide range is due to the irregular shape of the fibronectin molecule and the range of different positions in which it can adsorb. Clearly, the concentration of fibronectin in the coating solution used in these studies is within an order of magnitude of a saturating concentration and is not a limiting factor in adsorption.

Investigators should be aware of the poor efficiency of ECM adsorption to silicone-rubber membranes compared to the traditional tissue culture plastic. These differences in ECM adsorption can have a tremendous effect on cell adhesion and spreading, thus influencing the transmission of strain between the substrate and cell. A possible solution to this issue is simply to increase 
the amount of matrix initially added. Doubling the amount of added matrix to $2 \mu \mathrm{g} / \mathrm{cm}^{2}$ has significantly improved the cell adhesion in experiments performed in our laboratory. Besides simply increasing the amount of matrix on the surface, studies have suggested that higher surface densities of adsorbed molecules may stabilize the active conformation of the protein and reduce denaturation (7). Different surface treatments, such as high-energy gas plasma treatment, may also specifically enhance both the adsorption of the matrix molecules and their activity. Excluding the walls of the wells from contact with the coating solution (perhaps by coating with a drop of buffer held in place by surface tension) may also enhance adsorption by decreasing the competition for protein from the walls, which clearly adsorb fibronectin much more strongly.

\section{ACKNOWLEDGMENTS}

Financial support from the University of Michigan Cellular Biotechnology Training Program (grant no. NIH\# GM08353 to J.J.C.), the American Heart Association (Predoctoral Fellowship no. N001734 to J.N.), and the National Institutes of Health (grant no. RO1 DE13349 to D.M.) is gratefully acknowledged.

\section{REFERENCES}

1.Barbee, K.A., E.J. Macarak, and L.E. Thibault. 1994. Strain measurements in cultured vascular smooth muscle cells subjected to mechanical deformation. Ann. Biomed. Eng. 22:14-22.

2.Burridge, K., K. Fath, T. Kelly, G. Nuckolls, and C. Turner. 1988. Focal adhesions: transmembrane junctions between the extracellular matrix and the cytoskeleton. Annu. Rev. Cell Biol. 4:487-525.

3.Chien, S., S. Li, and Y.J. Shyy. 1998. Effects of mechanical forces on signal transduction and gene expression in endothelial cells. Hypertension 31:162-169.

4.DiMilla, P.A., S.M. Albelda, and J.A. Quinn. 1992. Adsorption and elution of extracellular matrix proteins on nontissue culture petri dishes. J. Colloid Interface Sci. 153:212225

5.Gilbert, J.A., P.S. Weinhold, A.J. Banes, G.W. Link, and G.L. Jones. 1994. Strain profiles for circular cell culture plates containing flexible surfaces employed to mechanical- ly deform cells in vitro. J. Biomech. 27:11691177.

6.Grinnell, F. 1978. Cellular adhesiveness and extracellular substrata. Intl. Rev. Cytol. 53:65144.

7.Grinnell, F. and M.K. Feld. 1981. Adsorption characteristics of plasma fibronectin in relationship to biological activity. J. Biomed. Mater. Res. 15:363-381.

8.Grinnell, F. and M.K. Feld. 1982. Fibronectin adsorption on hydrophilic and hydrophobic surfaces detected by antibody binding and analyzed during cell adhesion in serum-containing medium. J. Biol. Chem. 257:4888-4893.

9.Hung, C.T. and J.L. Williams. 1994. A method for inducing equi-biaxial and uniform strains in elastomeric membranes used as cell substrates. J. Biomech. 27:227-232.

10.Ingber, D.E. 1990. Fibronectin controls capillary endothelial cell growth by modulating cell shape. Proc. Natl. Acad. Sci. USA 87:3579-3583

11.Ingber, D.E. 1997. Tensegrity: the architectural basis of cellular mechanotransduction. Annu. Rev. Physiol. 59:575-599.

12.Jalali, S., Y.S. Li, M. Sotoudeh, S. Yuan, S. Li, S. Chien, and J.Y. Shyy. 1998. Shear stress activates p60src-Ras-MAPK signaling pathways in vascular endothelial cells. Arterioscler. Thromb. Vasc. Biol. 18:227-234.

13.Kim, B.S., J. Nikolovski, J. Bonadio, and D.J. Mooney. 1999. Cyclic mechanical strain regulates the development of engineered smooth muscle tissue. Nat. Biotechnol. 17:979-983.

14.Lee, A.A., T. Delhaas, L.K. Waldman, D.A. MacKenna, F.J. Villarreal, and A.D. McCulloch. 1996. An equibiaxial strain system for cultured cells. Am. J. Physiol. 271:C1400C1408.

15.MacKenna, D.A., F. Dolfi, K. Vuori, and E. Ruoslahti. 1998. Extracellular signal-regulated kinase and c-Jun NH2-terminal kinase activation by mechanical stretch is integrin-dependent and matrix-specific in rat cardiac fibroblasts. J. Clin. Invest. 101:301-310.

16.Massia, S.P. and J.A. Hubbell. 1991. An RGD spacing of $440 \mathrm{~nm}$ is sufficient for integrin $\alpha \mathrm{V} \beta$ 3-mediated fibroblast spreading and $140 \mathrm{~nm}$ for focal contact and stress fiber formation. J. Cell Biol. 114:1089-1100.

17.McFarland, C.D., S. Mayer, C. Scotchford, B.A. Dalton, J.G. Steele, and S. Downes. 1999. Attachment of cultured human bone cells to novel polymers. J. Biomed. Mater. Res. 44:1-11.

18.Neyfakh, A.A., I.S. Tint, T.M. Svitkina, A.D. Bershadsky, and V.I. Gelfand. 1983. Visualization of cellular focal contacts using a monoclonal antibody to $80 \mathrm{kD}$ serum protein adsorbed on the substratum. Exp. Cell Res. 149:387-396.

19.Nikolovski, J. and D.J. Mooney. 2000. Smooth muscle cell adhesion to tissue engineering scaffolds. Biomaterials 21:2025-2032.

20.Putnam, A.J., J.J. Cunningham, R.G. Dennis, J.J. Linderman, and D.J. Mooney. 1998. Microtubule assembly is regulated by externally applied strain in cultured smooth muscle cells. J. Cell Sci. 111:3379-3387.

21.Rothman, A., T.J. Kulik, M.B. Taubman,
B.C. Berk, C.W. Smith, and B. Nadal-Ginard. 1992. Development and characterization of a cloned rat pulmonary arterial smooth muscle cell line that maintains differentiated properties through multiple subcultures. Circulation 86:1977-1986.

22.Schaffer, J.L., M. Rizen, G.J. L'Italien, A. Benbrahim, J. Megerman, L.C. Gerstenfeld, and M.L. Gray. 1994. Device for the application of a dynamic biaxially uniform and isotropic strain to a flexible cell culture membrane. J. Orthop. Res. 12:709-719.

23.Simmons, C.A. and D.J. Mooney. Regulation of cellular response to mechanical signals by matrix design. In F. Guilak (Ed.), Funtional Tissue Engineering: The Role of Biomechanics. Springer-Verlag, New York. (In Press.)

24.Smith, P.G., K.E. Janiga, and M.C. Bruce. 1994. Strain increases airway smooth muscle cell proliferation. Am. J. Respir. Cell Mol. Biol. 10:85-90.

25.Sotoudeh, M., S. Jalali, S. Usami, J.Y. Shyy, and S. Chien. 1998. A strain device imposing dynamic and uniform equi-biaxial strain to cultured cells. Ann. Biomed. Eng. 26:181189.

26.Sumpio, B.E., A.J. Banes, L.G. Levin, and G. Johnson, Jr. 1987. Mechanical stress stimulates aortic endothelial cells to proliferate. J. Vasc. Surg. 6:252-256.

27.Underwood, P.A. and F.A. Bennett. 1989. A comparison of the biological activities of the cell-adhesive proteins vitronectin and fibronectin. J. Cell Sci. 93:641-649.

28.Underwood, P.A., J.G. Steele, and B.A. Dalton. 1993. Effects of polystyrene surface chemistry on the biological activity of solid phase fibronectin and vitronectin, analyzed with monoclonal antibodies. J. Cell Sci. 104:793-803

29.Vandenburgh, H.H. 1992. Mechanical forces and their second messengers in stimulating cell growth in vitro. Am. J. Physiol. 262:R350-355.

30.Wilson, E., K. Sudhir, and H.E. Ives. 1995. Mechanical strain of rat vascular smooth muscle cells is sensed by specific extracellular matrix/integrin interactions. J. Clin. Invest. 96:2364-2372.

Received 20 June 2001; accepted 2 December 2001.

Address correspondence to:

Dr. David J. Mooney

Department of Biologic and Materials Sciences

University of Michigan

5213 School of Dentistry

1011 N. University Avenue

Ann Arbor, MI 48109, USA

e-mail:mooneyd@umich.edu

For reprints of this or any other article, contact Reprints@BioTechniques.com 